\title{
In vitro study of RRS HA injectable mesotherapy/ biorevitalization product on human skin fibroblasts and its clinical utilization
}

This article was published in the following Dove Press journal:

Clinical, Cosmetic and Investigational Dermatology

23 February 2016

Number of times this article has been viewed

\section{Pierre-Antoine Deglesne* \\ Rodrigo Arroyo* \\ Evgeniya Ranneva \\ Philippe Deprez}

Research and Development, SKIN TECH PHARMA GROUP, Castelló d’Empúries, Spain

*These authors contributed equally to this work

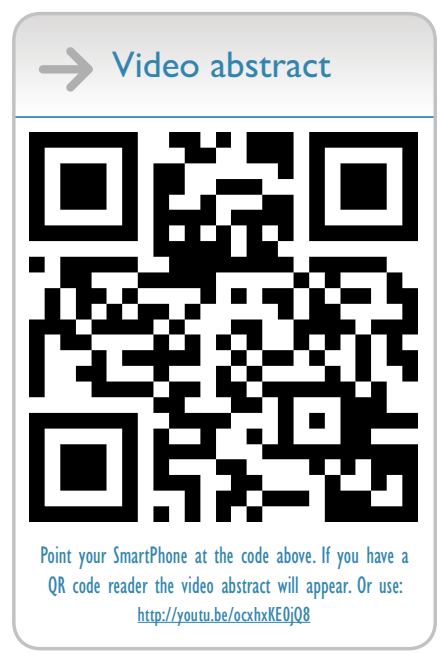

Correspondence: Philippe Deprez Research and Development, SKIN TECH PHARMA GROUP, C/Pla de l'Estany 29, 17486 Castelló d’Empúries, Spain Tel +34664385219

Email drdeprez@clinicahera.es
Abstract: Mesotherapy/biorevitalization with hyaluronic acid (HA) is a treatment approach currently used for skin rejuvenation. Various products with a wide range of polycomponent formulations are available on the market. Most of these formulations contain noncross-linked HA in combination with a biorevitalization cocktail, formed by various amounts of vitamins, minerals, amino acids, nucleotides, coenzymes, and antioxidants. Although ingredients are very similar among the different products, in vitro and clinical effects may vary substantially. There is a real need for better characterization of these products in terms of their action on human skin or in vitro skin models. In this study, we analyzed the effect of the RRS ${ }^{\circledR}$ (Repairs, Refills, Stimulates) HA injectable medical device on human skin fibroblasts in vitro. Skin fibroblast viability and its capacity to induce the production of key extracellular matrix were evaluated in the presence of different concentrations of RRS HA injectable. Viability was evaluated through colorimetric MTT (3-[4,5-dimethylthiazol-2-yl]-2,5 diphenyl tetrazolium bromide) assay, and key extracellular matrix genes, type I collagen and elastin, were quantified by quantitative polymerase chain reaction. Results demonstrated that RRS HA injectable could promote human skin fibroblast viability $(+15 \%)$ and increase fibroblast gene expression of type I collagen and elastin by 9.7 -fold and 14-fold in vitro, respectively. These results demonstrate that mesotherapy/ biorevitalization products can, at least in vitro, effectively modulate human skin fibroblasts.

Keywords: mesotherapy, medical device, RRS, collagen, elastin, extracellular matrix

\section{Introduction}

Mesotherapy is a minimally invasive technique that consists of local intradermal therapy (LIT) with pharmaceuticals or other substances. These substances are given in small quantities through multiple dermal punctures, where the injection site corresponds to the area of the pathological condition. ${ }^{1}$ The term "meso" from mesotherapy comes from the Greek word "mesos" referring to the mesoderm (or middle germ cell layer) in the early embryo, which differentiates into tissues and structures, including bone, cartilage, muscle, and connective tissue. ${ }^{2}$

Pharmacological products have been given intradermally for over a century, but it was not until much later that this method became more widely accepted. ${ }^{1-3}$ A French physician, Michel Pistor, reported encouraging results with small doses of drugs administered intradermally to patients with a variety of clinical conditions. ${ }^{1,2}$ Apart from the discovery of the method itself, one of the most relevant points is the fact that, for instance, in 1988, the French Academy of Medicine confirmed ${ }^{1}$ that this method is an integral part of classic medicine. 
Since the description of the technique, the use of LIT increased slowly during the first 20 years (1971-1991) but exponentially during the last 20 years. ${ }^{1}$ Clinical studies concerning LIT procedures used to treat pain confirm the efficacy and tolerability of anti-inflammatory/analgesic drugs administered using this technique. ${ }^{3}$ Nevertheless, the increased number of LIT procedures nowadays appears to be related in great part to skin rejuvenation purpose. Indeed, it is difficult to evaluate the number of aesthetic physicians using LIT procedures, which may vary from 10,000 to 40,000 worldwide depending on the source; in France alone, 122 physicians are registered as mesotherapists, but many more medical doctors are using the technique on a daily basis. ${ }^{4-7} \mathrm{Com}-$ pounds classically used in skin rejuvenation mesotherapy/ biorevitalization include noncross-linked hyaluronic acid (HA) or organic silicium as the principal ingredient and amino acids, vitamins, flavonoids, plant extracts, and others as secondary ingredients. ${ }^{8}{ }^{89}$ Although the procedure is widely used by aesthetic physicians, there is a considerable lack of scientific information related to the clinical efficiency of such skin rejuvenation mesotherapeutic products.

In European countries, injectable mesotherapeutic products are classified as CE (European Conformity) class III medical devices to ensure the safety of the final user and the subsequent follow-up of the product once on the market. Most of the companies proposing mesotherapy/biorevitalization products for skin rejuvenation claim temporal filler effect due to noncross-linked HA, and subsidiary claims may include biorevitalization, dermal moisturizing, dermal regeneration, extracellular matrix (ECM) strengthening, or collagen booster effect. Nevertheless, very little in vitro data supporting these subsidiary claims can be found in the scientific literature.

In this study, we present the in vitro results that were generated by an independent, external, certified laboratory regarding the effect of RRS ${ }^{\circledR}$ (Repairs, Refills, Stimulates) HA injectable mesotherapy/biorevitalization product from the company SKIN TECH PHARMA GROUP. The experiments were carried out in order to determine the effect of RRS HA injectable on human fibroblast viability and expression of type I collagen, and elastin genes in vitro.

\section{Materials and methods MTT assay}

Human skin fibroblasts (BJ cells) were seeded at 7,000 cells/ well in 24-well cell culture plates and allowed to grow in Dulbecco's Modified Eagle's Medium supplemented with $10 \%$ fetal bovine serum (FBS) for 24 hours at $37^{\circ} \mathrm{C}$ with $5 \%$ $\mathrm{CO}_{2}$. The cells underwent starvation in serum-free medium for 6 hours before treatment. Next, the cells were exposed to the tested sample at the specified concentrations $(0.2 \mathrm{mg} / \mathrm{mL}$ and $1 \mathrm{mg} / \mathrm{mL}$ ) in fresh medium without FBS and incubated for 24 hours or 48 hours. Cells treated with the medium alone were used as negative control, and cells treated with $100 \mu \mathrm{g} / \mathrm{mL}$ of human insulin were used as positive control. All dilutions were tested in triplicate. No ethics statement was required from the institutional review board for the use of these cell lines.

After cell treatment, cell survival was determined using the MTT (3-[4,5-dimethylthiazol-2-yl]-2,5 diphenyl tetrazolium bromide) assay. Briefly, $300 \mu \mathrm{L}$ of MTT solution was added into each well and incubated for 3 hours at $37^{\circ} \mathrm{C}$. The medium was removed, the precipitated blue formazan dye was dissolved in isopropanol or dimethyl sulfoxide $(300 \mu \mathrm{L}$ per well), and the absorbance was quantified spectrophotometrically at $550 \mathrm{~nm}$. The plate was shaken on a gyratory plate shaker to ensure that all the crystals dissolved and formed a homogeneous solution. The absorbance was measured on a microplate reader (Tecan modello Sunrise remote), with background clearing. Results were expressed as follows:

$$
\begin{aligned}
& \% \text { of the cell viability } \\
& =\frac{[\mathrm{OD}(550 \mathrm{~nm}-690 \mathrm{~nm}) \text { of tested product }}{\mathrm{OD}(550 \mathrm{~nm}-690 \mathrm{~nm}) \text { of negative control }]} \times 100
\end{aligned}
$$

\section{RNA extraction, real-time and quantitative polymerase chain reaction}

Human skin-derived normal fibroblasts (American Type Culture Collection CRL-2522) were seeded at 10,000 cells/well in 24-well cell culture plates and allowed to grow in minimum essential medium supplemented with $10 \%$ FBS for 24 hours at $37^{\circ} \mathrm{C}$ with $5 \% \mathrm{CO}_{2}$. The cells underwent starvation in serum-free medium for 6 hours before treatment. Next, the cells were exposed to scalar dilutions of the tested products $(0.2 \mathrm{mg} / \mathrm{mL}$ and $1 \mathrm{mg} / \mathrm{mL})$ in fresh serum-free medium. The culture medium containing the sample was replaced daily. Untreated cells were used as negative control; cells treated with human insulin were used as positive control, and all experiments were performed in triplicate.

After 24 hours and 48 hours of exposure, total RNA was extracted using a guanidine thiocyanate-based reagent according to the manufacturer's instructions (TRIZOL). After precipitation and centrifugation ( $30 \mathrm{~min}, 12,000 \mathrm{rpm}, 4^{\circ} \mathrm{C}$ ), RNA was resuspended in $20 \mu \mathrm{L}$ of sterile water and its concentration was determined spectrophotometrically. Then, $300 \mathrm{ng}$ of total RNA was retrotranscribed into complementary DNA 
using random primers at $37^{\circ} \mathrm{C}$ for 2 hours in a thermal cycler following the manufacturer's instructions (Thermo Fisher Scientific, Waltham, MA, USA). Changes in gene expression profile were analyzed by "real-time polymerase chain reaction" technology using a SYBR green-based chemistry. Primer pair sequences used for type I collagen and elastin gene amplification as well as the normalizer actin were designed by Eurofins (Eurofins BioPharma Product Testing Spain SLU, Barcelona, Spain). Calculation of the fold change was done in a two-step calculation according to the following formulas:

1. $\Delta \mathrm{CT}=\mathrm{CT}$ (target) $-\mathrm{CT}$ (normalizer)

2. Fold change $=2-\Delta \mathrm{CT}$.

\section{Statistical analysis}

GraphPad software was used for graphical representation of the data and statistical analysis. Unpaired $t$-test was used to determine the $P$-value and statistical significance. Normality testing was done using Anderson-Darling normality test. $P$-values $\leq 0.05$ were considered as statistically significant.

\section{Bibliographic revision and search algorithm}

A search in PubMed database from The National Library of Medicine (NLM) using specific MeSH headings was done. MeSH term was retrieved for mesotherapy but neither for biorevitalization nor for bio-revitalization terms. The search algorithm used was as follows: "Mesotherapy" [Mesh], 47 abstracts retrieved. A simple PubMed search with mesotherapy as a term allowed retrieving 186 abstracts that contained all previously identified abstracts. Further search in PubMed using biorevitalization $(n=1)$, biorevitalization $(n=4)$, mesotherapic $(n=2)$, mesoterapica $(n=2)$, and mesotherapy $(n=2)$ allowed the identification of 12 more abstracts. Finally, nine more abstracts were manually added. Then, the pool of 216 abstracts was reviewed and analyzed, of which 85 abstracts were related to medical indications such as pain treatment, 61 to adverse events occurring with mesotherapy procedures, and 70 were directly related to the use of mesotherapy for aesthetic purpose. Among the abstracts describing the use of mesotherapy for aesthetic purpose, 29 described procedures related to fat reduction, four related to alopecia, 20 related to skin rejuvenation, ten related to adverse events, and ten related to other types of aesthetic procedures. In addition, among the 29 abstracts related to skin rejuvenation procedures, two in vitro studies, one animal model, four expert opinion, and 13 clinical studies were identified (Supplementary material).

\section{Results \\ RRS HA injectable medical device, indication, and clinical survey}

RRS HA injectable is a resorbable medical device using a long-chain (average 2.8 million Da), medical-grade, noncrosslinked HA at a final concentration of $6.66 \mathrm{mg} / \mathrm{mL}$ for filling superficial dermis together with a dermal biorevitalization. This medical device is indicated for skin antiage regeneration, tired atonic skin, and fine wrinkles. The HA employed is from nonanimal origin. The biorevitalization solution is composed of vitamins, fatty acids, coenzymes, antioxidants, polyphenols, amino acids, and trace elements.

RRS HA injectable is normally used to treat face/neck and décolletage using not only a microdermal papule injection technique (needle $30 \mathrm{G} 1 / 2$ or $32 \mathrm{G}$ ) but also, more recently, blunt cannulas that allow reduction of entry points and ecchymoses. Classically, $5 \mathrm{~mL}$ of the product is injected per area per session. The total number of sessions may vary from four to six with a frequency of one session per week. Figure 1 presents one example of application of RRS HA injectable on the face and neck.

Market survey (claim procedure according to ISO 13485) did not register any claim for this product since 2013 .
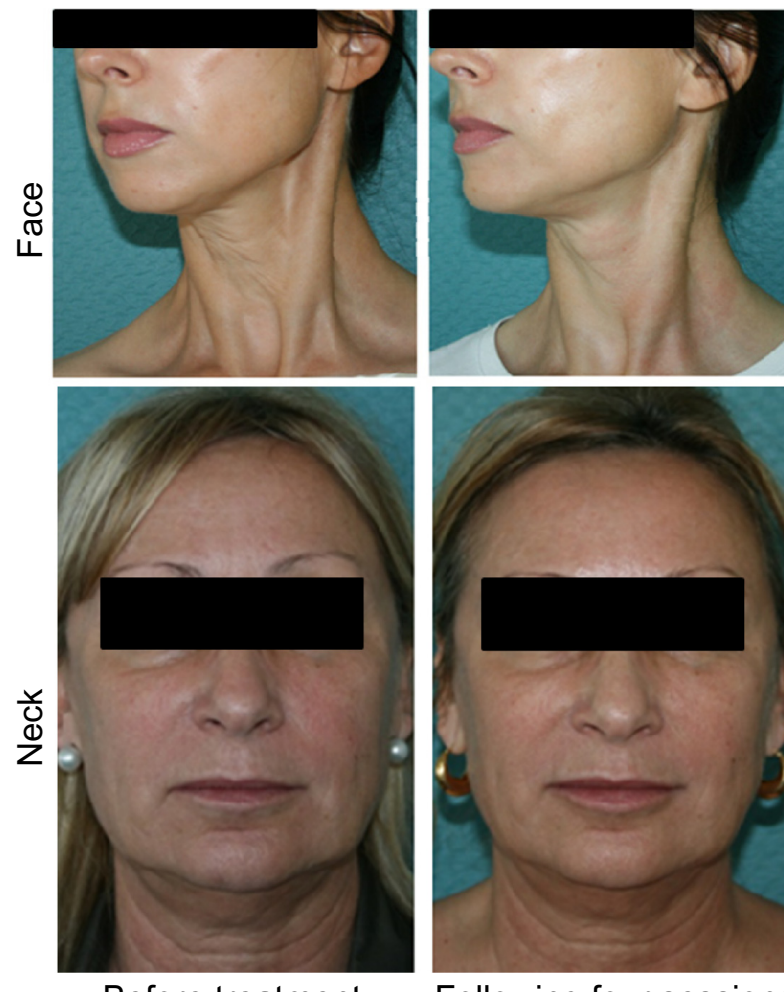

Before treatment

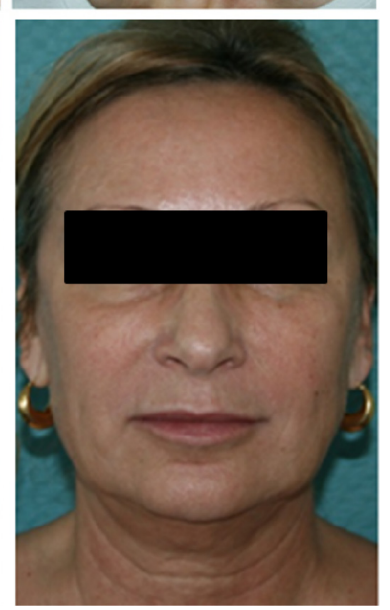

Following four sessions

Figure I Example of application of RRS ${ }^{\circledast}$ (Repairs, Refills, Stimulates) hyaluronic acid injectable on the face and neck. 


\section{RRS HA injectable promotes human fibroblast viability}

Dermal fibroblasts ensure the production of the ECM components composing the dermal connective tissue responsible for the skin's tensile strength and mechanical properties..$^{10}$ Therefore, all the in vitro experiments were carried out on primary human fibroblasts as they represent the main cellular population of human dermis skin compartment.

We first evaluated the effect of RRS HA injectable on human fibroblast viability using MTT assay on resting synchronized serum-starved human fibroblasts. The assay was done in the presence of two different concentrations of the RRS HA injectable $(0.2 \mathrm{mg} / \mathrm{mL}$ and $1 \mathrm{mg} / \mathrm{mL})$ and compared to two control conditions, one lacking RRS HA injectable (unstimulated control) and the other activated with $100 \mu \mathrm{m} / \mathrm{mL}$ of human insulin (stimulated control). Two different time points were evaluated, at 24 hours and 48 hours, posttreatment with RRS HA injectable.

The results demonstrated that RRS HA injectable was not toxic to human fibroblasts in vitro at none of the doses $(0.2 \mathrm{mg} / \mathrm{mL}$ and $1 \mathrm{mg} / \mathrm{mL})$ and at none of the time points tested ( 24 hours and 48 hours). Moreover, we found that RRS HA injectable supported cell viability of human fibroblasts up to $15.8 \% \pm 3.9 \%$ as measured by the MTT assay at 48 hours in the presence of $1 \mathrm{mg} / \mathrm{mL}$ of RRS HA injectable (Figure 2).

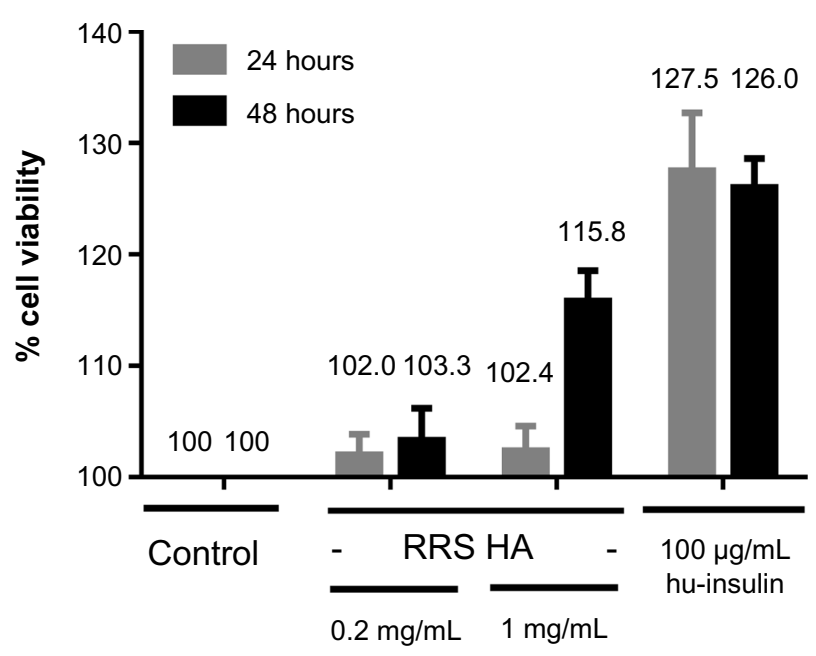

Figure 2 Cell viability of human fibroblasts cultured in vitro in the presence of two concentrations $(0.2 \mathrm{mg} / \mathrm{mL}$ and $\mathrm{I} \mathrm{mg} / \mathrm{mL})$ of $\mathrm{RRS}^{\circledR} \mathrm{HA}$ injectable evaluated using MTT assay at 24 hours (gray color) and 48 hours (black color) posttreatment.

Notes: As positive control, human fibroblasts were activated with $100 \mu \mathrm{g} / \mathrm{mL}$ of human insulin. Results are expressed as the percentage of viability compared to negative control.

Abbreviation: HA, hyaluronic acid; RRS ${ }^{\circledR}$, Repairs, Refills, Stimulates.

\section{RRS HA injectable promotes the synthesis of type I collagen and elastin gene transcripts by human fibroblasts}

The dermis is largely composed of dense collagen-rich ECM. Dermal collagen represents by far the most abundant ECM protein and constitutes the bulk of skin (90\% dry weight). ${ }^{11,12}$ Among the five types of collagen present in the skin, type I collagen represents $80 \%$ of the total content and is therefore the main structural collagen type in the skin. ${ }^{13}$ Another $15 \%$ is represented by type III collagen and was shown to participate in skin healing. ${ }^{14}$ Moreover, a network of elastic fibers in the ECM of these tissues gives them the required resilience to recoil after stretching. The main component of elastic fibers is the elastin molecule that creates a natural cross-linking to adjacent elastin molecules.

Collagen dermis content is believed to represent dermis thickness, while elastin content represents the elastic properties of the skin. Therefore, we evaluated the expression of type I collagen and elastin genes on synchronized serum-starved human fibroblasts in the presence or absence of different concentrations of RRS HA injectable at two different time points ( 24 hours and 48 hours). Gene expression was assessed by quantitative polymerase chain reaction assay as described in the "Materials and methods" section. As for MTT assay, human fibroblasts were synchronized using serum starvation. Two control conditions were used for subsequent comparison with RRS HA injectable culture conditions, one negative control (lacking RRS HA injectable) and one positive control (culture in the presence of $50 \mu \mathrm{g} / \mathrm{mL}$ of human insulin).

Results were expressed as a fold increase in gene transcript expression among the activated condition and control condition. RRS HA injectable was able to effectively increase the expression of messenger RNA codifying for type I collagen and elastin as early as 24 hours in the presence of $1 \mathrm{mg} / \mathrm{mL}$ of the product ( $4.37 \pm 0.64$ and $5.1 \pm 1.39$, respectively). The maximum increase of expression was observed at 48 hours for both type I collagen (9.7 \pm 2.44$)$ and elastin $(14.3 \pm 2.55)$ in the presence of $1 \mathrm{mg} / \mathrm{mL}$ of the product. Interestingly, even low concentrations of RRS HA injectable $(0.2 \mathrm{mg} / \mathrm{mL})$ were able to increase the expression of both type I collagen and elastin (4.5 \pm 1.18 and $3.6 \pm 0.84$, respectively) at 48 hours posttreatment (Figure 3).

\section{Discussion}

Our results demonstrated that RRS HA injectable promotes human skin fibroblast viability and enhances the expression of type I collagen and elastin genes in vitro. The relevance 
A Collagen type I gene transcript expression

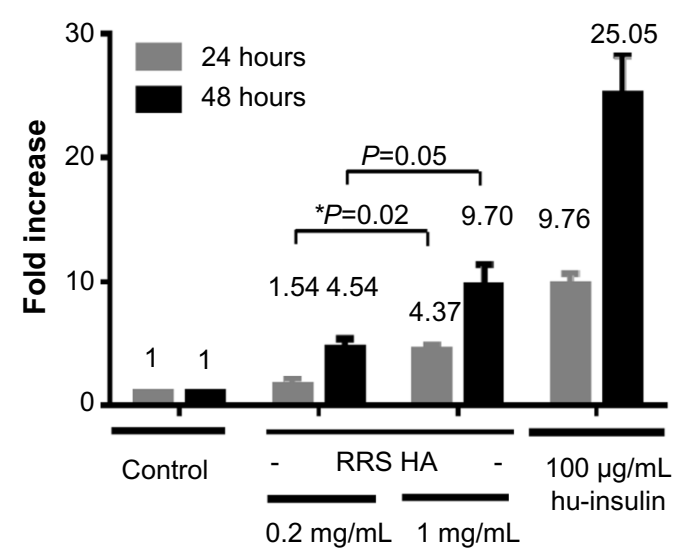

B Elastin gene transcript expression

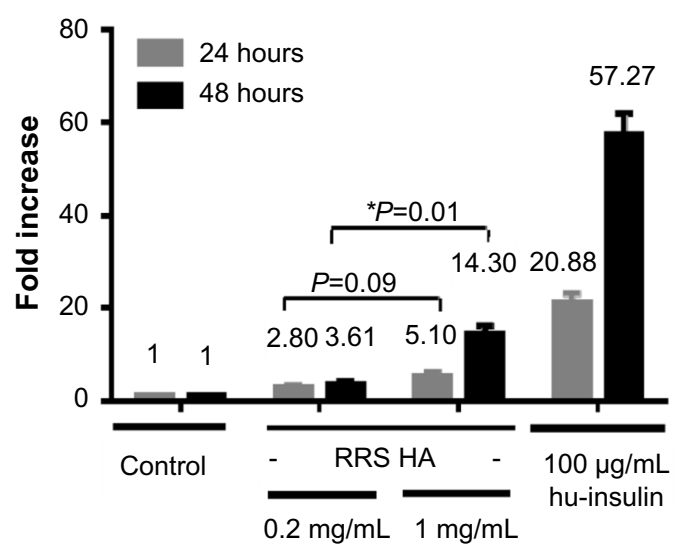

Figure 3 Effect on the expression of type I collagen and elastin genes.

Notes: Evaluation of type I collagen and elastin transcript expression of human fibroblasts cultured in vitro in the presence of two concentrations $(0.2 \mathrm{mg} / \mathrm{mL}$ and I $\mathrm{mg} / \mathrm{mL})$ of RRS ${ }^{\circledast} \mathrm{HA}$ injectable evaluated using quantitative PCR at 24 (gray color) and 48 (black color) hours posttreatment. Results are expressed as a fold increase of the gene transcript expression against the control condition (without treatment). As positive control, human fibroblasts were activated with $100 \mu g / \mathrm{mL}$ of human insulin. (A) Collagen type I transcript expression in the different culture conditions. (B) Elastin transcript expression in the different culture conditions.

Abbreviations: PCR, polymerase chain reaction; HA, hyaluronic acid; RRS ${ }^{\circledR}$, Repairs, Refills, Stimulates.

of using in vitro studies to characterize the action of mesotherapy/biorevitalization products, classified as CE class III medical devices, is justified, as the product is directly injected into the dermis compartment where it will be in contact with dermal fibroblasts. Viability results from an in vitro experiment on human fibroblasts with RRS HA injectable are in line with preclinical tests that were performed with the product for the delivery of the CE class III certificate. These tests, described in Table 1, demonstrate the biocompatibility and lack of toxicity of the RRS HA injectable medical device. They are part of the CE class III medical device evaluation and are done to ensure further patient safety and have to be passed for the product to have a chance to be approved.

Histological and ultrastructural studies have revealed that the major alterations in aged skin are encountered in the dermal ECM. ${ }^{15}$ In young skin (20-30 years), intact collagen fibrils are abundant, tightly packed, and well organized, whereas in aged skin ( $>80$ years), the collagen fibrils are fragmented and disorganized. Investigations have revealed that the characteristic features of aging of the skin connective tissue are largely

Table I Preclinical tests performed with RRS HA injectable

\begin{tabular}{ll}
\hline Test & Guideline \\
\hline Tests for in vitro cytotoxicity on mammal fibroblast & ISO I0993-5: 2009 \\
Tests for systemic toxicity & ISO I0993-I I: 2006 \\
Intracutaneous reactivity test & ISO I0993-10: 20I0 \\
Tests for irritation and delayed-type hypersensitivity & ISO I0993-I0: 20I0 \\
Genotoxicity, carcinogenicity toxicity assays & ISO I0993-3: 20I4 \\
\hline
\end{tabular}

Note: List of biocompatibility studies performed for the RRS ${ }^{\circledR}$ product on cell lines, animals, and bacteria.

Abbreviations: RRS ${ }^{\circledR}$, Repairs, Refills, Stimulates; HA, hyaluronic acid. due to aberrant collagen homeostasis. ${ }^{16}$ Two interrelated mechanisms are involved: reduced collagen biosynthesis and increased collagen fibril fragmentation. Moreover, degeneration in the elastic fiber network has also been reported as a characteristic feature of aging skin. Networks of elastic fibers, which are composed of elastin molecules, in the ECM of these tissues give them the required resilience to recoil after stretching and are thus responsible for skin elasticity. In this in vitro study, we found that RRS HA injectable could promote a nearly tenfold increase in type I collagen gene expression and a 14-fold increase in elastin gene expression demonstrating that in vitro RRS HA injectable promotes ECM production of key proteins by acting on skin fibroblasts. Nevertheless, the mechanisms leading to the induction of expression of collagen or elastin synthesis by-products containing HA are poorly understood. Studies using nonanimal cross-linked HA suggest that HA could promote fibroblast tension, resulting in their activation. ${ }^{17}$

Our bibliographic review on mesotherapy/biorevitalization identified ten clinical studies out of 13 , reporting beneficial effects on skin rejuvenation, ${ }^{18-26}$ which include improvement of skin hydration, skin elasticity, skin anisotropy, skin roughness, and skin complexion radiance. A reduction in the number and depth of wrinkles was also demonstrated. Moreover, skin biopsy after 3 months showed a decrease in interleukin-1 $\beta$, interleukin- 6 , and matrix metalloproteinase-1 (MMP1) and an increase in type I collagen and elastic fibers. ${ }^{23}$ Nevertheless, two clinical studies evaluating both skin properties and histological biopsies did not find any significant benefit of mesotherapy/biorevitalization for skin 
rejuvenation..$^{27,28}$ These discordant results may be explained by the fact that formulations used in all those eleven studies were all very different; some combining noncross-linked HA with a biorevitalization solution, whereas others using only HA or organic silicon. Moreover, biorevitalization solution formulas may greatly vary between fabricants.

Diverse effects of mesotherapy/biorevitalization products on skin rejuvenation have also been demonstrated in vitro by Jäger et al. ${ }^{29}$ Indeed, they found that some products preserved the viability of normal human skin fibroblasts while stimulating type I collagen, MMP1, and tissue inhibitor of MMP1 production, whereas other products led to apoptosis and/or necrosis of human fibroblasts. More recently, these diverse effects of mesotherapy/biorevitalization products on skin rejuvenation were again emphasized by Avantaggiato et al. ${ }^{30}$ They found that there was an association between the HA content of the products and the expression of elastin and elastase genes. In that study, higher HA concentrations were associated with lower elastin gene activation but higher expression of elastase gene. However, genes encoding for hyaluronan synthase 1, hyaluronidase 1 , and desmoplakin, although enhanced in culture in the presence of the different products, did not appear to be related to the HA content of the different products. The negative effect is eventually related to some of the other components of the solution used for this study. They concluded that it is important for the physician to choose which medical devices can be used in relation to the effect expected.

\section{Conclusion}

In conclusion, we suggest that as the number of these products is currently increasing, there is a real need to evaluate their safety and efficiency. This study demonstrated that RRS HA injectable promotes human skin fibroblast viability and enhances the expression of type I collagen and elastin genes in vitro.

\section{Acknowledgments}

All in vitro experiments and collection of data corresponding to the experiments were performed by Eurofins BioPharma Product Testing Spain SLU, an external independent certified laboratory. This manuscript has been revised by Eurofins to validate that all the described data conform to their results. Patient pictures were kindly provided by Dr Jane Ranneva after obtaining informed consent from the patients.

\section{Author contributions}

All authors made substantial contributions to conception and design; took part in either drafting the article or revising it critically for important intellectual content; gave final approval of the version to be published; and agree to be accountable for all aspects of the work in ensuring that questions related to the accuracy or integrity of any part of the work are appropriately investigated and resolved.

\section{Disclosure}

All four authors are working for SKIN TECH PHARMA GROUP and elaborated the design of the experiments and the redaction of the following manuscript. Nevertheless, all in vitro experiments and collection of data corresponding to the experiments were performed by Eurofins BioPharma Product Testing Spain SLU, an external independent certified laboratory. This manuscript has been revised by Eurofins to validate that all the described data conform to their results. The authors report no other conflicts of interest in this work.

\section{References}

1. Sivagnanam G. Mesotherapy/biorevitalization - the French connection. J Pharmacol Pharmacother. 2010;1(1):4-8.

2. Herreros FO, Moraes AM, Velho PE. Mesotherapy: a bibliographical review. An Bras Dermatol. 2011;86(1):96-101.

3. Mammucari M, Gatti A, Maggiori S, Sabato AF. Role of mesotherapy/ biorevitalization in musculoskeletal pain: opinions from the Italian society of mesotherapy/biorevitalization. Evid Based Complement Alternat Med. 2012;2012:436959.

4. Mesotherapy [webpage on the Internet]. Bayonne, NJ: International Society of Cosmetogynecology. Available from: http://www.iscgyn. com/en/procedures_mesotherapy. Accessed December 08, 2015.

5. Qué es la mesoterapia [What is Mesotherapy]. Sociedad Española de Mesoterapia Médica. Available from: http://www.semm.es/que-es-lamesoterapia/. Accessed December 08, 2015. Spanish.

6. Skin and Beauty Services in Bedford [webpage on the Internet]. Available from: http://www.5deparysdental.co.uk/prgf-vampire-facialbedford.html. Accessed November 2, 2015.

7. SFM [homepage on the Internet]. Available from: http://www. sfmesotherapie.com/. Accessed November 2, 2015.

8. Prikhnenko S. Polycomponent mesotherapy/biorevitalization formulations for the treatment of skin aging and improvement of skin quality. Clin Cosmet Investig Dermatol. 2015;8:151-157.

9. Sturm LP, Cooter RD, Mutimer KL, Graham JC, Maddern GJ. A systematic review of dermal fillers for age-related lines and wrinkles. ANZ J Surg. 2011;81(1-2):9-17.

10. Darby IA, Laverdet B, Bonté F, Desmoulière A. Fibroblasts and myofibroblasts in wound healing. Clin Cosmet Investig Dermatol. 2014;7: 301-311.

11. Quan T, Fisher GJ. Role of age-associated alterations of the dermal extracellular matrix microenvironment in human skin aging: a minireview. Gerontology. 2015;61:427-434.

12. Li Y, Lei D, Swindell WR, et al. Age-associated increase in skin fibroblast-derived prostaglandin E(2) contributes to reduced collagen levels in elderly human skin. J Invest Dermatol. 2015;135(9):2181-2188.

13. Diegelmann RF. Collagen metabolism. Wounds. 2001;13:177-182.

14. Leung A, Crombleholme TM, Keswani SG. Fetal wound healing: implications for minimal scar formation. Curr Opin Pediatr. 2012;24(3): 371-378.

15. Quan T, Little E, Quan H, Qin Z, Voorhees JJ, Fisher GJ. Elevated matrix metalloproteinases and collagen fragmentation in photodamaged human skin: impact of altered extracellular matrix microenvironment on dermal fibroblast function. J Invest Dermatol. 2013;133(5):1362-1366. 
16. Quan T, Qin Z, Robichaud P, Voorhees JJ, Fisher GJ. CCN1 contributes to skin connective tissue aging by inducing age-associated secretory phenotype in human skin dermal fibroblasts. J Cell Commun Signal. 2011;5(3):201-207.

17. Quan T, Wang F, Shao Y, et al. Enhancing structural support of the dermal microenvironment activates fibroblasts, endothelial cells, and keratinocytes in aged human skin in vivo. J Invest Dermatol. 2013; 133(3):658-667.

18. Herreros FO, Cintra ML, Adam RL, de Moraes AM, Metze K. Remodeling of the human dermis after application of salicylate silanol. Arch Dermatol Res. 2007;299(1):41-45.

19. Lacarrubba F, Tedeschi A, Nardone B, Micali G. Mesotherapy/ biorevitalization for skin rejuvenation: assessment of the subepidermal low-echogenic band by ultrasound evaluation with cross-sectional B-mode scanning. Dermatol Ther. 2008;21(Suppl 3):S1-S5.

20. Rozhanets AR, Turova EA, Kul'chitskaia DB. Combined application of electric myo-stimulation and meso-therapy for the correction of age-related changes of the facial skin. Vopr Kurortol Fizioter Lech Fiz Kult. 2010;4:26-30.

21. Taieb M, Gay C, Sebban S, Secnazi P. Hyaluronic acid plus mannitol treatment for improved skin hydration and elasticity. J Cosmet Dermatol. 2012;11(2):87-92.

22. Baspeyras M, Rouvrais C, Liégard L, et al. Clinical and biometrological efficacy of a hyaluronic acid-based mesotherapy/biorevitalization product: a randomised controlled study. Arch Dermatol Res. 2013; 305(8):673-682.

23. Savoia A, Landi S, Baldi A. A new minimally invasive mesotherapy/ biorevitalization technique for facial rejuvenation. Dermatol Ther (Heidelb). 2013;3(1):83-93.
24. Liu S, Chen Z, Cai X, et al. Effects of dimethylaminoethanol and compound amino acid on D-galactose induced skin aging model of rat. Scientific World Journal. 2014;2014:507351.

25. Tedeschi A, Lacarrubba F, Micali G. Mesotherapy/biorevitalization with an intradermal hyaluronic acid formulation for skin rejuvenation: an intrapatient, placebo-controlled, long-term trial using high-frequency ultrasound. Aesthetic Plast Surg. 2015;39:129-133.

26. Sparavigna A, Tenconi B, De Ponti I. Antiaging, photoprotective, and brightening activity in biorevitalization: a new solution for aging skin. Clin Cosmet Investig Dermatol. 2015;8:57-65.

27. Amin SP, Phelps RG, Goldberg DJ. Mesotherapy for facial skin rejuvenation: a clinical, histologic, and electron microscopic evaluation. Dermatol Surg. 2006;32(12):1467-1472.

28. El-Domyati M, El-Ammawi TS, Moawad O, et al. Efficacy of mesotherapy/biorevitalization in facial rejuvenation: a histological and immunohistochemical evaluation. Int J Dermatol. 2012;51(8): 913-919.

29. Jäger C, Brenner C, Habicht J, Wallich R. Bioactive reagents used in mesotherapy/biorevitalization for skin rejuvenation in vivo induce diverse physiological processes in human skin fibroblasts in vitroa pilot study. Exp Dermatol. 2012;21(1):72-75.

30. Avantaggiato A, Girardi A, Palmieri A, Pascali M, Carinci F. Comparison of bio-revitalizing injective products: a study on skin fibroblast cultures. Rejuvenation Res. 2015;8(3):270-276. 


\section{Supplementary material}

Table SI Review details about the abstracts related to skin rejuvenation and mesotherapy

\begin{tabular}{|c|c|c|c|c|c|c|}
\hline Authors & PMID & Year & Study type & Product tested & $\begin{array}{l}\text { Patient } \\
\text { number }\end{array}$ & $\begin{array}{l}\text { Interventional/ } \\
\text { observational }\end{array}$ \\
\hline Amin et al' & 17199654 & 2006 & $\begin{array}{l}\text { Open label } \\
\text { clinical trial }\end{array}$ & Multivitamin and hyaluronic acid (HA) solution & 10 & Interventional \\
\hline lorizzo et $\mathrm{al}^{2}$ & 18472058 & 2008 & Expert opinion & - & - & - \\
\hline $\begin{array}{l}\text { Herreros } \\
\text { et } \mathrm{al}^{3}\end{array}$ & 17333223 & 2007 & $\begin{array}{l}\text { Open label } \\
\text { clinical trial }\end{array}$ & $0.1 \%$ salicylate silanol & 7 & Interventional \\
\hline $\begin{array}{l}\text { Lacarrubba } \\
\text { et } \mathrm{al}^{4}\end{array}$ & 19076625 & 2008 & $\begin{array}{l}\text { Open label } \\
\text { clinical trial }\end{array}$ & HA salts of biotechnological origin $(I, 000 \mathrm{kDa})$ & 20 & Interventional \\
\hline $\begin{array}{l}\text { Rozhanets } \\
\text { et al }\end{array}$ & 21086592 & 2010 & $\begin{array}{l}\text { Randomized } \\
\text { clinical trial }\end{array}$ & MT and electrostimulation (EMS) & 60 & Interventional \\
\hline Braccini et $\mathrm{al}^{6}$ & 21284223 & 2010 & Expert opinion & - & - & - \\
\hline Sturm et $\mathrm{al}^{7}$ & 21299793 & 2011 & Review & - & - & - \\
\hline Jäger et $\mathrm{al}^{8}$ & 22151394 & 2012 & $\begin{array}{l}\text { Experimental } \\
\text { in vitro }\end{array}$ & $\begin{array}{l}\text { NCTFI } 35^{\circledR} \text { and } \mathrm{NCTFI} 35 \mathrm{HA}^{\circledR} \text {, Soluvit }{ }^{\circledR} \mathrm{N} \text { and } \\
\text { Meso-BK }\end{array}$ & - & - \\
\hline Taieb et $\mathrm{al}^{9}$ & 22672272 & 2012 & $\begin{array}{l}\text { Open label } \\
\text { clinical trial }\end{array}$ & $\begin{array}{l}\text { I3.5 mg/g uncross-linked } \mathrm{HA}+0.9 \% \text { mannitol } \\
(\mathrm{HA}+\text { mannitol })\end{array}$ & 34 & Interventional \\
\hline $\begin{array}{l}\text { El-Domyati } \\
\text { et al }{ }^{10}\end{array}$ & 22788806 & 2012 & Clinical & Revitacare $^{\circledast}$, Bio-Revitalization & 6 & Interventional \\
\hline Turova et al" ${ }^{\prime \prime}$ & 22994060 & 2012 & Clinical & Procaine & 95 & Interventional \\
\hline $\begin{array}{l}\text { Baspeyras } \\
\text { et al }{ }^{12}\end{array}$ & PMC3778226 & 2013 & $\begin{array}{l}\text { Randomized } \\
\text { clinical trial }\end{array}$ & Glytone ${ }^{\circledast}$ I professional, Merz Pharmaceutical GmbH & 55 & Interventional \\
\hline
\end{tabular}




\begin{tabular}{|c|c|c|}
\hline Efficiency analysis & Side effects & Results \\
\hline $\begin{array}{l}\text { Photographs evaluation/histology/electron } \\
\text { microscopic analysis of collagen fibers } \\
\text { measurements }\end{array}$ & No side effects & $\begin{array}{l}\text { Mesotherapy (MT) does not appear to provide any significant } \\
\text { benefit }\end{array}$ \\
\hline- & - & - \\
\hline $\begin{array}{l}\text { The histological features of punch biopsies } \\
\text { of the treated area and the nontreated } \\
\text { contralateral arm were compared and the } \\
\text { collagen and elastic fibers quantified }\end{array}$ & No side effects & $\begin{array}{l}\text { The application of silicon may stimulate the production of } \\
\text { collagen and elastic fibers }\end{array}$ \\
\hline $\begin{array}{l}\text { Ultrasound evaluation with cross-sectional } \\
\text { B-mode scanning }\end{array}$ & No side effects & $\begin{array}{l}\text { A statistically significant }(P<0.00 \mathrm{I}) \text { increase of SLEB } \\
\text { echogenicity (with a mean increase of pixel numbers equal to } \\
31.3 \% \text { ) was observed in } 15 \text { of } 19 \text { subjects who completed the } \\
\text { study }\end{array}$ \\
\hline $\begin{array}{l}\text { Well-being-Activity-Mood test/Skin XP Pro } \\
\text { system and skin microcirculation by laser } \\
\text { Doppler flowmetry (LDF) }\end{array}$ & No side effects & $\begin{array}{l}\text { The results of the study indicate that combined MT + EMS } \\
\text { therapy significantly improves the state of facial skin, decreases } \\
\text { its pigmentation, reduces the number and depth of wrinkles, } \\
\text { enhances skin moisture, improves its elasticity, and decreases } \\
\text { porosity }\end{array}$ \\
\hline- & - & - \\
\hline- & - & - \\
\hline $\begin{array}{l}\text { Collagen expression, cell proliferation, and } \\
\text { morphological changes using normal human } \\
\text { skin fibroblast cultures in vitro }\end{array}$ & - & $\begin{array}{l}\text { Cell proliferation was comparable to control cultures in the } \\
\text { presence of hyaluronic acid, NCTFI } 35^{\circledR} \text { and NCTFI } 35 \mathrm{HA}^{\circledast} \text {; } \\
\text { moreover, a higher expression of collagen type-I, } \\
\text { matrix metalloproteinase-I and tissue inhibitor of matrix } \\
\text { metalloproteinase-I was noticed in the presence of those } \\
\text { products. In comparison, addition of Soluvit }{ }^{\circledR} \mathrm{N} \text { and Meso-BK } \\
\text { led to apoptosis and/or necrosis of human fibroblasts. }\end{array}$ \\
\hline Evaluation form/physician skin evaluation & No side effects & $\begin{array}{l}\mathrm{HA}+\text { mannitol is effective for skin hydration, anisotropy, and } \\
\text { roughness when treated using a depot technique but not with } \\
\text { picotage technique }\end{array}$ \\
\hline Photographs/skin biopsies & No side effects & $\begin{array}{l}\text { The clinical evaluation of volunteers at baseline, end of } \\
\text { treatment, and } 3 \text { months posttreatment revealed no significant } \\
\text { differences. Histological and immunostaining analysis of types I, } \\
\text { III, and VII collagen, newly synthesized collagen, total elastin, } \\
\text { and tropoelastin showed no statistically significant changes } \\
(P>0.05) \text { after MT injection }\end{array}$ \\
\hline Biological age & No side effects & $\begin{array}{l}\text { The study revealed the most significant decrease of the } \\
\text { biological age (calculated as described by LM Belozerova) } \\
\text { in the patients treated with procaine electrophoresis ( } 91 \% \\
\text { improvement). The mesotherapeutic administration of procaine } \\
\text { also produced the beneficial effect ( } 59 \% \text { improvement). Neither } \\
\text { procaine galvanization nor placebo MT caused any significant } \\
\text { change of the variables characterizing the biological age }\end{array}$ \\
\hline $\begin{array}{l}\text { Photographs/skin elasticity was measured } \\
\text { using a Cutometer }{ }^{\circledR} \text { MPA } 580 / \text { dermis } \\
\text { thickness was measured by echography using a } \\
\text { high-frequency }(20 \mathrm{MHz}) \text { ultrasound scanner }\end{array}$ & $\begin{array}{l}87.7 \% \text { experienced one or several } \\
\text { adverse effects after injection. } \\
\text { Adverse events were generally of } \\
\text { mild or moderate intensity and } \\
\text { expected (hematoma, edema, } \\
\text { papule, erythema, or other } \\
\text { transient inflammatory reactions): } \\
46.8 \% \text { occurred in the HA-treated } \\
\text { hemiface and } 25.7 \% \text { in the control }\end{array}$ & $\begin{array}{l}\text { Dermis thickness significantly increased after } \mathrm{HA} \text { treatment } \\
\text { at I } \mathrm{M}(+3.4 \%, P=0.028) \text { and } 3 \mathrm{M}(+4 \%, P=0.008) \text { and after } \\
\text { control treatment at I } \mathrm{M} \text { only }(+2.5 \%, P=0.015) \text {. The HA filler } \\
\text { significantly improved complexion radiance at } 3 \mathrm{M} \text { compared } \\
\text { with the control }(P=0.012) \text { and for } 5 \mathrm{I} \% \text { of subjects, their } \\
\text { skin status. Nonreticulated } \mathrm{HA} \text {-based } \mathrm{MT} \text { significantly and } \\
\text { sustainably improves skin elasticity and complexion radiance }\end{array}$ \\
\hline
\end{tabular}

(Continued) 
Table SI (Continued)

\begin{tabular}{|c|c|c|c|c|c|c|}
\hline Authors & PMID & Year & Study type & Product tested & $\begin{array}{l}\text { Patient } \\
\text { number }\end{array}$ & $\begin{array}{l}\text { Interventional/ } \\
\text { observational }\end{array}$ \\
\hline Savoia et $\mathrm{al}^{13}$ & PMC3680640 & 2013 & Clinical & $\begin{array}{l}\text { Formulation A, tocopherol, arginine, sodium chloride, } \\
\text { adenine, inositol, sodium hyaluronate, ubiquinone, } \\
\text { lysine, cytosine, acetyl cysteine, water, cyanocobalamin, } \\
\text { isoleucine, glutamine, polysorbate } 20 \text {, folic acid, leucine, } \\
\text { guanine, riboflavin, threonine } \\
\text { Pyridoxine HCL, valine, thiamine HCL, histidine } \\
\text { hydrochloride, nicotinamide, tyrosine, calcium } \\
\text { pantothenate, phenylalanine, ascorbic acid, glutamic acid, } \\
\text { aspartic acid, asparagine, cysteine, proline, serine, alanine, } \\
\text { methionine, glycine, tryptophan } \\
\text { Formulation B, which was composed of HA, idebenone, } \\
\text { polysorbate } 20 \text {, water, acetyl cysteine, sodium chloride }\end{array}$ & 50 & Interventional \\
\hline Liu et $\mathrm{al}^{14}$ & PMC4I 23624 & 2014 & Animal model & $\begin{array}{l}\text { Intradermal microinjection of saline, } 3.48 \% \text { amino acids } \\
(\mathrm{AA}), 0.1 \% \mathrm{DMAE}, 0.2 \% \mathrm{DMAE}, 0.1 \% \mathrm{DMAE}+\mathrm{AA} \text {, or } \\
0.2 \% \mathrm{DMAE}+\mathrm{AA}\end{array}$ & - & - \\
\hline $\begin{array}{l}\text { El-Domyati } \\
\text { et } \mathrm{al}^{15}\end{array}$ & $255 \mid 4823$ & 2015 & Clinical & $\begin{array}{l}\text { Different noninvasive modality for the treatment of skin } \\
\text { aging, including radiofrequency, Nd: YAG I320-nm laser } \\
\text { and Er: YAG 2940-nm laser mini-peels, intense pulsed } \\
\text { light (IPL), MT injection, and electrooptical synergy }\end{array}$ & 36 & \\
\hline $\begin{array}{l}\text { Tedeschi } \\
\text { et } \mathrm{al}^{16}\end{array}$ & 25539986 & 2014 & $\begin{array}{l}\text { Clinical, placebo } \\
\text { controlled }\end{array}$ & MT with $\mathrm{HA}$ & 22 & Interventional \\
\hline
\end{tabular}




\begin{tabular}{l} 
Efficiency analysis \\
\hline Punch biopsies were taken from randomly \\
selected participants, baseline, and after \\
6 weeks, and stained for interleukin (IL)-6, \\
IL-I $\beta$, MMPI, and collagen type I. Clinical \\
evaluation was based on the Global Aesthetic \\
Scale (GAIS) and on the Wrinkle Severity \\
Rating Scale (WSRS)
\end{tabular}

Histology TGF- $\beta$

High-frequency ultrasound $(22 \mathrm{MHz}$ ) was performed to evaluate SLEB echogenicity changes during treatment
The induced erythema was graded $24 \pm 4$ hours after irradiation, according to the COLIPA reference visual score: $0=$ no erythema, $\mathrm{I} / 2=$ perceptible redness reaction (MED), I= moderate erythema, 2 = severe erythema. Visual scores of every response to MED-testing were then compared with the ones obtained by irradiated skin previously injected with the study product and irradiated skin previously injected with a placebo (physiological solution for injection). UVB irradiation corresponding to I MED was performed 24 hours after the study product/placebo microinjection, and clinical evaluation of the induced erythema was scored $24 \pm 4$ hours after irradiation. The photoprotective efficacy was expressed as a percentage of erythema visual score variation vs placebo.

Side effects $\quad$ Results

No side effects

$-$

No side effects

Only one adverse event occurred during the trial: on the day after the second injection procedure, one subject showed edema on the lower eyelids, more marked on the right side, which resolved a few days after the application of an anti-inflammatory cream
The results produced were statistically analyzed and resulted in a significant and long-lasting effect on facial rejuvenation. Evaluation of photographs at 0,1 , and 2 months revealed significant clinical improvement: brightness, texture, and firmness of the skin. The analysis of the GAIS and WSRS scores in the two groups demonstrated statistically significant results after 2 months. The biopsies taken from randomly selected participants at baseline and after 3 months showed a decrease in IL-I $\beta$, IL-6, and MMPI and an increase in collagen I

Expression of types I and II collagen and MMPI was highly upregulated in both $0.1 \%$ DMAE + AA and 0.2\% DMAE + AA groups compared with aging control. In contrast, TIMP-I expression levels of various aging groups were significantly reduced when compared to sham control

However, no significant differences $(P>0.05)$ were observed in TGF- $\beta$ level in response to IPL or MT treatments in comparison with baseline

Eighteen of 22 patients completed the study. At the end of 4 weeks, an ultrasound increase of dermal echogenicity was observed in 13 subjects (seven of group A and six of group B), which we considered as "responders." In these patients, the Student's $t$-test showed a significant increase from baseline of SLEB pixel numbers of $+24 \%(P<0.0$ I $)$ versus $+6 \%$ with placebo. In the same subjects, after an additional 4 months of monthly injections, the mean increase was $+18 \%(P<0.05)$ versus $+4 \%$ with placebo. In patients from group $B$ who completed 10 months of treatment, the increase from baseline of SLEB pixel numbers was $+18 \%(P<0.05)$ versus $0 \%$ with placebo Instrumental assessment showed, as early as after the second biorevitalizing treatment, the antiaging efficacy of the tested product; there was a clinical and statistically significant improvement of profilometric parameters, skin brightness, pigmentation, and deep skin hydration. The study product induced a statistically significant decrease of the visual score of the UVB-induced erythema compared with baseline, which was statistically different from placebo $-$ 
Table SI (Continued)

\begin{tabular}{|c|c|c|c|c|c|c|}
\hline Authors & PMID & Year & Study type & Product tested & $\begin{array}{l}\text { Patient } \\
\text { number }\end{array}$ & $\begin{array}{l}\text { Interventional/ } \\
\text { observational }\end{array}$ \\
\hline $\begin{array}{l}\text { Avantaggiato } \\
\text { et al }{ }^{19}\end{array}$ & 25640228 & 2015 & $\begin{array}{l}\text { Experimental } \\
\text { in vitro }\end{array}$ & $\begin{array}{l}\text { Five different commercial medical devices containing } \\
6.2 \mathrm{mg} / \mathrm{mL}, 10 \mathrm{mg} / \mathrm{mL}, 10 \mathrm{mg} / \mathrm{mL}, 13 \mathrm{mg} / \mathrm{mL} \text {, and } \\
20 \mathrm{mg} / \mathrm{mL} \text {, respectively, of HA }\end{array}$ & - & - \\
\hline
\end{tabular}

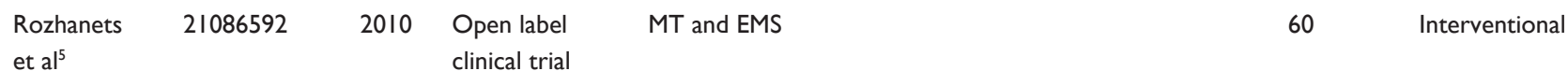

Abbreviations: SLEB, subepidermal low echogenicity band; TGF, transforming growth factor; PMID, PubMed identification; PMC, PubMed Central; IPL, intense pulsed light; M, month; PCR, polymerase chain reaction; DMAE, dimethylethanolamine; TIMP-I, metallopeptidase inhibitor I; RT-PCR, reverse transcription polymerase chain reaction; LDF, laser doppler flowmetry.

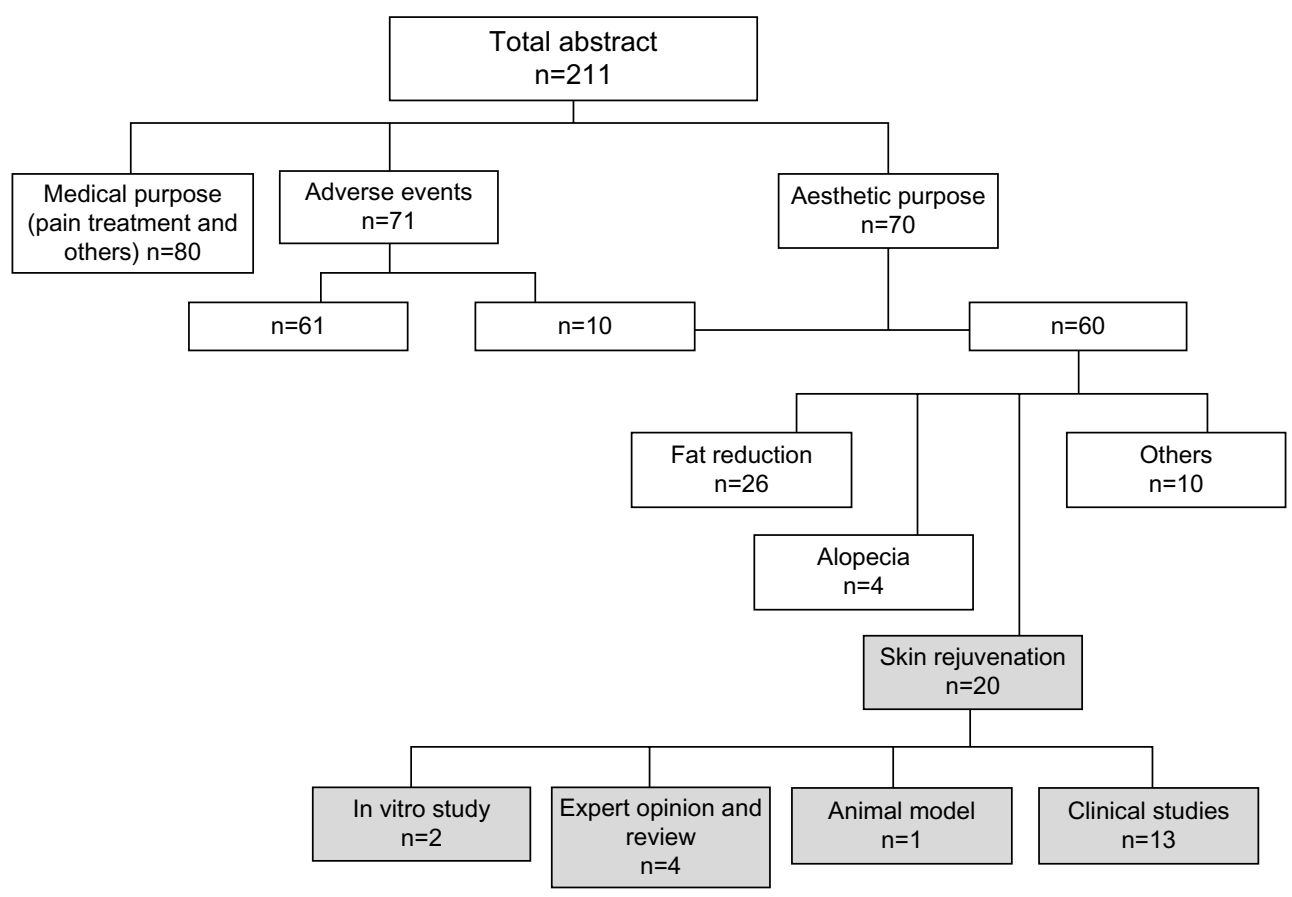

Figure SI Analysis of the 21 I selected abstracts.

Notes: Abstracts were individually revised for specific topics (medical use of the mesotherapy/biorevitalization, adverse events, aesthetic purpose, including fat reduction, alopecia, and skin rejuvenation). Finally, abstracts on skin rejuvenation were separated into four groups, including in vitro studies, expert opinions/reviews, animal models, and clinical studies. Original paper for each abstract within the skin rejuvenation group was retrieved and analyzed.

\section{References}

1. Amin SP, Phelps RG, Goldberg DJ. Mesotherapy for facial skin rejuvenation: a clinical, histologic, and electron microscopic evaluation. Dermatol Surg. 2006;32(12):1467-1472.

2. Iorizzo M, De Padova MP, Tosti A. Biorejuvenation: theory and practice. Clin Dermatol. 2008;26(2):177-181.
3. Herreros FO, Cintra ML, Adam RL, de Moraes AM, Metze K. Remodeling of the human dermis after application of salicylate silanol. Arch Dermatol Res. 2007;299(1):41-45.

4. Lacarrubba F, Tedeschi A, Nardone B, Micali G. Mesotherapy/biorevitalization for skin rejuvenation: assessment of the subepidermal lowechogenic band by ultrasound evaluation with cross-sectional B-mode scanning. Dermatol Ther. 2008;21(Suppl 3):S1-S5. 


\begin{tabular}{|c|c|c|}
\hline Efficiency analysis & Side effects & Results \\
\hline RT-PCR and PCR & - & $\begin{array}{l}\text { HA concentration seems to be inversely correlated to elastin } \\
\text { gene activation. Regarding the neutrophil elastase gene, the two } \\
\text { medical devices with the higher concentration of HA displayed } \\
\text { the greater effect. Genes encoding for hyaluronan synthase I, } \\
\text { hyaluronidase I, and desmoplakin were enhanced, but the HA } \\
\text { content of the different products did not seem to be directly } \\
\text { related to gene activation. Therefore, the explanation for the } \\
\text { differences must be studied further with respect to elements } \\
\text { that are distinctive for each device }\end{array}$ \\
\hline $\begin{array}{l}\text { Facial skin conditions were assessed using a } \\
\text { Skin XP Pro system and skin microcirculation } \\
\text { by LDF. The psychological status of the } \\
\text { patients was evaluated with the help of the } \\
\text { Well-being-Activity-Mood test }\end{array}$ & - & $\begin{array}{l}\text { The results of the study indicate that combined MT + EMS } \\
\text { therapy significantly improves the state of facial skin, decreases } \\
\text { its pigmentation, reduces the number and depth of wrinkles, } \\
\text { enhances skin moisture, improves its elasticity, and decreases } \\
\text { porosity }\end{array}$ \\
\hline
\end{tabular}

5. Rozhanets AR, Turova EA, Kul'chitskaia DB. Combined application of electric myo-stimulation and meso-therapy for the correction of age-related changes of the facial skin. Vopr Kurortol Fizioter Lech Fiz Kult. 2010;4:26-30.

6. Braccini F, Dohan Ehrenfest DM. [Advantages of combined therapies in cosmetic medicine for the treatment of face aging: botulinum toxin, fillers and mesotherapy]. Rev Laryngol Otol Rhinol (Bord). 2010;131(2):89-95. French.

7. Sturm LP, Cooter RD, Mutimer KL, Graham JC, Maddern GJ. A systematic review of dermal fillers for age-related lines and wrinkles. $A N Z$ J Surg. 2011;81(1-2):9-17.

8. Jäger C, Brenner C, Habicht J, Wallich R. Bioactive reagents used in mesotherapy/biorevitalization for skin rejuvenation in vivo induce diverse physiological processes in human skin fibroblasts in vitro-a pilot study. Exp Dermatol. 2012;21(1):72-75.

9. Taieb M, Gay C, Sebban S, Secnazi P. Hyaluronic acid plus mannitol treatment for improved skin hydration and elasticity. J Cosmet Dermatol. 2012;11(2):87-92.

10. El-Domyati M, El-Ammawi TS, Moawad O, et al. Efficacy of mesotherapy/biorevitalization in facial rejuvenation: a histological and immunohistochemical evaluation. Int J Dermatol. 2012;51(8):913-919.

11. Turova EA, Konchugova TV, Balaban EI, Fadeeva NI, Golovach AV, Teniaeva EA. [The influence of procaine electrophoresis and mesotherapy on the characteristics of biological age]. Vopr Kurortol Fizioter Lech Fiz Kult. 2012;4:19-22. Russian.

12. Baspeyras M, Rouvrais C, Liégard L, et al. Clinical and biometrological efficacy of a hyaluronic acid-based mesotherapy/biorevitalization product: a randomised controlled study. Arch Dermatol Res. 2013;305(8):673-682.
13. Savoia A, Landi S, Baldi A. A new minimally invasive mesotherapy/ biorevitalization technique for facial rejuvenation. Dermatol Ther (Heidelb). 2013;3(1):83-93.

14. Liu S, Chen Z, Cai X, et al. Effects of dimethylaminoethanol and compound amino acid on D-galactose induced skin aging model of rat. Scientific World Journal. 2014;2014:507351.

15. El-Domyati M, El-Ammawi TS, Medhat W, Moawad O, Mahoney MG, Uitto J. Expression of transforming growth factor- $\beta$ after different non-invasive facial rejuvenation modalities. Int $J$ Dermatol. 2015;54(4):396-404.

16. Tedeschi A, Lacarrubba F, Micali G. Mesotherapy/biorevitalization with an intradermal hyaluronic acid formulation for skin rejuvenation: an intrapatient, placebo-controlled, long-term trial using high-frequency ultrasound. Aesthetic Plast Surg. 2015;39:129-133.

17. Sparavigna A, Tenconi B, De Ponti I. Antiaging, photoprotective, and brightening activity in biorevitalization: a new solution for aging skin. Clin Cosmet Investig Dermatol. 2015;8:57-65.

18. Prikhnenko S. Polycomponent mesotherapy/biorevitalization formulations for the treatment of skin aging and improvement of skin quality. Clin Cosmet Investig Dermatol. 2015;8:151-157.

19. Avantaggiato A, Girardi A, Palmieri A, Pascali M, Carinci F. Comparison of bio-revitalizing injective products: a study on skin fibroblast cultures. Rejuvenation Res. 2015;8(3):270-276.
Clinical, Cosmetic and Investigational Dermatology

\section{Publish your work in this journal}

Clinical, Cosmetic and Investigational Dermatology is an international, peer-reviewed, open access, online journal that focuses on the latest clinical and experimental research in all aspects of skin disease and cosmetic interventions. All areas of dermatology will be covered; contributions will be welcomed from all clinicians and

\section{Dovepress}

basic science researchers globally. This journal is indexed on CAS. The manuscript management system is completely online and includes a very quick and fair peer-review system, which is all easy to use. Visit http://www.dovepress.com/testimonials.php to read real quotes from published authors. 